\title{
"GUNN'S DOTS"
}

To the Editor of The British Journal of Ophthalmology SIR,

Your annotation on this subject, and Mr. Paton's letter thereon, remind me of an instance which happened to myself when working with Mr. Nettleship some thirty or more years back. For I quite unconsciously re-discovered these dots when examining the fundus of a patient who had recently been exhibiting symptoms of night-blindness, and, thinking I had found a physical basis for nyctalopia, I joyfully approached Mr. Nettleship with the news of my discovery. Immediate was the reply from that accurate observer, "Are you acquainted with 'Gunn's dots,' Taylor?" Well, I wasn't and felt crushed.

I have noticed them a good many times since then, and mainly above and below and to the nasal side of the O.D., never towards the periphery of the fundus, and scarcely at all in the macular region.

One must look a little obliquely at the area where they are, and not straight at it, and, of course, by the direct method only.

They are found in youngish people, and are generally noticed by accident when looking for something else.

I do not think any symptoms are definitely and invariably associated with them; but " asthenopia," like "Mesopotamia," is a useful and precious word.

Yours, etc.,

S. JOHNSON TAYLOR.

NoRwich,

March 16, 1918.

P.S.- I find no mention of them in Fuchs's admirable text-book of 1911.

\section{THE EXTRACTION OF CATARACT}

\section{To the Editor of THE BRITISH JOURNAL OF OPHTHALMOLOGY}

SiR,-The last half of Dr. Johnson Taylor's letter in the February number of the JOURNAL, regarding the comparative merits and dangers of the simple as against the combined extraction, in his own words, "should not pass unnoticed."

To take his various points in order:

1. Cosmetic gain. No cosmetic reason should take precedence over safety, and this advantage may therefore be dismissed at once if there is any risk.

2. Scarcely any pain during and much less after operation. 